The Politics of Fractal Geometry in Russian Paper Architecture: The Intelligent Market and The Cube of Infinity.

Michael J Ostwald

\begin{abstract}
Fractal geometry has been used repeatedly in architectural design throughout the last 20 years either because it is not Euclidean or because it has some capacity to simulate nature. While these properties explain the majority of projects that borrow from complexity science, a small number of designs also utilise fractal geometry for political purposes. This paper examines the political dimension of fractal geometry in two projects from the Russian Paper Architecture movement. Through this analysis the paper supports Robin Evans' contention that misunderstandings of the mathematical properties of geometry can lead to the production of architecture that is conceptually unstable.
\end{abstract}

\title{
Architectural Appropriations
}

In 1977, the first English language edition of scientist and mathematician Benoit Mandelbrot's seminal work Fractals: Form, Chance, and Dimension was published to much critical acclaim. In this book Mandelbrot coined the term 'fractal' to describe non-integer dimensions. 'Fractal comes from the Latin adjective fractus, which has the same root as fraction and fragment and means "irregular or fragmented"; it is related to frangere, which means "to break",.1 In general terms, fractal geometry may be used to describe irregular or complex lines, surfaces and volumes that defy description through the use of simple Euclidean geometry. Paradoxically, fractal geometry cannot be used to describe completely random or stochastic forms, but only those that possess characteristic or regular irregularly. $^{2}$

Less than 12 months after the publication of Fractals: Form, Chance, and Dimension, Peter Eisenman exhibited his House 11a for the first time. ${ }^{3}$ A few weeks later, in July of 1978, House 11a became a central thematic motif in Eisenman's housing scheme produced during the Cannaregio design seminar in Venice. ${ }^{4}$ Although this project was not exhibited until April 1980, it nevertheless marks the first widely published appropriation of fractal geometry by an architect. $^{5}$ Specifically, Eisenman appropriates the concept of fractal scaling - a process that he describes as entailing 'three destabilizing concepts: discontinuity, which confronts the metaphysics of presence; recursivity, which confronts origin; and self-similarity, which confronts representation and the aesthetic object' ${ }^{6}$ In the 
almost 30 years that followed, more than 200 architectural designs or works of architectural theory have been published which have laid claim, in some way, to aspects of fractal geometry. ${ }^{7}$

Ignoring, for the moment, the inherent futility of any and all attempts to actually render architecture fractal, ${ }^{8}$ designers have repeatedly been drawn to appropriate concepts from fractal geometry to serve two theoretical agendas. Firstly, they appropriate fractal geometry in an attempt to undermine architecture's Euclidean orthodoxy and secondly they appropriate to connect their designs more closely to nature. In the former case, fractal geometry is fundamentally a new form of geometry that seems to dislocate Euclidean geometry from its historic position of centrality. Thus, architects seeking some way of rejecting the canonical virtues of architecture - being symmetrical and constructed of Euclidean shapes or Phileban solids - have been drawn to fractal geometry with its apparent antihierarchical structure. ${ }^{9}$ In the latter case, because fractal geometry appears capable of simulating natural structures (trees, mountain ranges, coastlines) and systems (population fluctuations, economic cycles, static) it is especially seductive for architects attempting to design buildings which mediate between humanity and nature. ${ }^{10}$ This second dimension is predictable given the long history of biological analogy in Western architecture. ${ }^{11}$ Both of these dimensions of fractal geometry (that is, being not Euclidean and being related to nature) explain the majority, but not all of the appropriations made by architects from chaos theory. There is one other characteristic, the potential political dimension of fractal geometry, which also invites such appropriations. The political dimension of fractal geometry in architecture is apparent in a range of appropriations made by architects in the Soviet Union in the 1980s. These architects, working largely in isolation, produced a series of works inspired by, or actively produced through, fractal manipulations of geometry. While it is possible to argue that these architects utilized fractal geometry because it is either not Euclidean or natural, it is the political dimension of these appropriations that is most intriguing.

This paper commences with an overview of classical fractal geometry and three fractal geometric icons that play an important role in Russian Paper Architecture. Thereafter, the application of fractal geometry in two specific examples - Turin's The Intelligent Market and Bush, Podyapolsky and Khomyakov's The Cube of Infinity — is considered. This process identifies and examines the political application of the geometric form to determine whether it undermines the conceptual intentions of the design — what Robin Evans describes as testing the stability of the design's theoretical foundations. ${ }^{12}$ This question of theoretical stability becomes important when seen in the light of Evans' assertion that the extent of the architect's understanding of geometry is manifest in the disjunction between the design as it is expressed (in drawings and models) and the design as it is espoused (in the writings of the architect). Evans maintains that new forms of geometry are always immediately appropriated from 
mathematics and used by architects regardless of whether or not they are well understood. The danger of this practice is that if the appropriated concept (in this case, fractal geometry) is poorly understood it may destabilize the theoretical foundations of the design and simultaneously undermine the critical intentions of the architect.

\section{Classical Fractal Sets}

There are two broad types of fractals. The first type are called 'classical', 'pure', 'ideal' or 'self-same'. They are simplified or archetypal manifestations of the properties of fractal geometry. As these fractals are constructed of Euclidean geometric forms they are purely hypothetical because such forms (two dimensional and delineated by one dimensional lines) cannot exist in the real world. These fractals are of theoretical interest because they display the essential characteristics of fractal form relatively clearly. The second type of fractals are called 'self-similar' or 'statistical' fractals. These are the geometric sets used to simulate natural forms. This paper is primarily concerned with the former type, the classical fractal, and its architectural application. This is because there tends to be clear evidence when an architect has used one of these iconic forms to generate or decorate a design. ${ }^{13}$ While many architects have claimed that their buildings have been inspired by statistical or selfsimilar fractals, inspiration is more difficult to assess than appropriation. Thus, for example, while Aldo and Hannie van Eyck and Ushida Findlay have each acknowledged designing buildings that seek to mimic some of the visual qualities of 'natural' fractal sets, they also admit that this is just one of multiple themes they are developing in a particular design project. ${ }^{14}$ Similarly, while there are various examples of Russian Paper architecture that appear to be inspired by 'statistical' fractal sets (including multiple designs from Sergei Chuklov and Vera Chuklova) the present paper is concerned with those examples where the appropriation is most readily apparent and these tend to be from classical fractal sets.

Three examples of classical fractals that are useful in illustrating the general properties of non-linear geometry are the Cantor point-set, the Koch island and the Sierpinski carpet. Each of these geometric sets are part of the tradition of irrational number theory and each has grown out of studies of mathematical phenomenon that were at the time considered 'pathological' ${ }^{15}$ because they defied conventional mathematical logic.

The Cantor point-set (which is also known as Cantor dust or the Cantor triadic bar) was first proposed in 1870; it involves two components - a line, or very thin bar, and a simple transformative principle that is repeated indefinitely. The transformative rule takes the bar or line and removes the middle one- 
third from it leaving behind two separate lines. The transformative rule is then applied to these two lines, removing the middle one-third of each and breaking them down into four; then it is applied to the four new lines creating eight and so on (see figure 1). After the transformative rule is repeated an infinite number of times the line is converted into a 'dust' of points - minuscule broken portions of the line. What made this process disturbing from a mathematical perspective is that it produced an infinite number of points of dust that have a total length of almost zero. It is this paradox that lead Victorian scientists to view these curves as monstrous or pathological.

In 1904 the Swedish mathematician Helge von Koch described an iterative geometric transformation that relied upon a simple system of rules but which produced a graphically deep and complex outcome that has since become known as the Koch island or Koch curve. The construction of the Koch island commences with two components, an equilateral triangle and a transformative rule. The transformative rule takes the middle one-third of each side of an equilateral triangle and attaches another equilateral triangle to it using the middle one-third length as a generator. At the first stage or first iteration of this transformation, the starting triangle resembles a Star of David. As Gleick notes, the shape now has six points instead of three. Gleick continues; '[n]ow take each of the twelve sides and repeat the transformation, attaching a smaller triangle onto the middle third. Now again, and so on to infinity. ${ }^{16}$ As more and more transformations take place the figure becomes increasingly detailed and begins to resemble an ideal snowflake (see figures 2 and 3).

The Koch island is notable for a number of reasons. Firstly, it has almost infinite length because as the number of transformations continue the perimeter of the object approaches infinity. However, if a circle is drawn around the Koch triadic island, the points of the shape would never protrude beyond the circle. This implies that the shape has a finite area; as the perimeter length approaches infinity the area of the Koch triadic island merely approaches the area of the circle. To extrapolate this further, in the Koch island an infinitely long perimeter defines an almost finite area. Furthermore, as the mathematician Brian Kaye observes, the Koch island has another important characteristic.

If one were to take a portion of the perimeter of Koch's triadic island and look at it under a microscope, the magnified portion would look exactly the same as the original large part of the boundary [...] This 'look-alike' feature of an ideal fractal boundary at various magnifications is described by the mathematician as self-similarity. Thus an important property of an ideal fractal curve is that it is self-similar at any magnification. ${ }^{17}$

The Sierpinski carpet is another classical fractal set formed from a starting geometric figure and an iterative progression. Named after its creator, the Polish mathematician Waclaw Sierpinski, the Sierpinski carpet commences with a square and a transformative rule that states that the middle one- 
third of the square is to be deleted. This can be visualised by imagining that the starting square is divided into a three by three grid creating nine squares. The middle square is the one deleted leaving behind eight others. While the Koch curve is additive, in that small triangles are added to the sides of the starting figure, the Sierpinski carpet and the Sierpinski triangle are subtractive. The transformation is then repeated on the remaining eight squares and so on (see figure 4).

The three-dimensional version of the Sierpinski carpet, the Sierpinski sponge (or more commonly known as the Menger sponge ${ }^{18}$ ) has the intriguing property that it has an almost infinite surface area and yet almost no volume (see figure 5). As John Rajchman records, the Sierpinski sponge is between the properties of surface and volume.

Each square hole is surrounded by eight holes which are a third of its size. Each of these eight holes is then surrounded by another set of eight holes. The operation is repeated ad infinitum resulting in a hollow cube for which the total volume approaches zero while the total lateral surface infinitely grows. Thus the cube lies between a surface with a dimension of two and a volume with a dimension of three. ${ }^{19}$

\section{Politics and Paper Architecture}

Between 1989 and 1991 the Deutsches Architektur Museum supported a major touring exhibition (across North America and parts of Europe) of the work of a number of young Russian architects. ${ }^{20}$ The exhibition, entitled Paper Architecture, was almost entirely made up of unbuilt designs, often competition entries, which were executed on paper during the nineteen eighties. These elaborate, fantasy designs, ostensibly completed in opposition to the laws of the state, were soon branded as the Russian Paper Architecture movement. ${ }^{21}$

In the exhibition catalogue, Heinrich Klotz records how he initially thought that much of the Russian paper architecture grew from the era of glasnost and perestroika. Yet when he questioned the architects about their designs they suggested, instead that their work had formed throughout the Brezhnev era. Klotz states that it 'was under Brezhnev's rule that all those rigid, large buildings that have disfigured Moscow's image were erected — those huge fortifications of state-owned enterprises, that have even surpassed the Western disaster of "glass-box architecture”, ${ }^{22}$ It is this brutal totalitarian built environment that lead these architects to 'rebel against the petrification and to mobilize counterforces on paper. Their 'paper architecture' [is] not the result of a stimulus arising from the new situation, but a protest against a corrupted state architecture of former years' ${ }^{23}$ Klotz's sentiments are echoed in Mikhail Belov's assertion that these works 'are not yet the fruits of perestroika - these will 
be harvested in the future. Rather, they are all the "children of the stagnation", who have grown up in spite of it'. ${ }^{24}$

Alexander Rappaport describes the paper architecture as a reaction against socialist attempts to create a utopian cityscape in Russia. The nature of totalitarian architecture, he states, 'lies not only in gigantism or in the cult of power but also in a normative monotony which evolves in the course of a systematic realisation of utopias. ${ }^{25}$ For Rappaport, the Russian paper architecture of the Brezhnev era is not utopian; rather it is a rebellious expression of fantasy. Rappaport argues that while there appear to be similarities between fantasy and utopia, the main difference is that fantasy architecture does not argue for a solution to real world social and political problems.

Fantasy proceeds from the principle of a pluralistic world and the variety of the spatial conditions of human life. The spatiality of concrete fantasy is limited. It can be valid for a dictated as well as for an agreed upon location. The theatricality of fantasy is obvious; it emphasizes its relativity [...] The differences between utopia and fantasy relating to time categories are analogous. The time of utopia is either 'eternity', an era of the past (the 'Golden Age') or of the future ('the happy future') which does not possess logical reversibility. Fantasy is, in large measure arbitrary; it can appear and disappear. ${ }^{26}$

Given this background, what, then, is the connection to fractal geometry? In attempting to break away from the totalitarian architectural impulse for monotony, the projects by the Soviet paper architects draw on a range of iconic forms which attack Euclidean geometry (the symbol of the state authorised architecture) and which personify the power of imagination and fantasy. Fractal geometry is seemingly ideal for this purpose as it embodies both complexity and infinite depth. Brian Hatton notes this thematic preoccupation and begins to draw a connection to fractal geometry when he proposes that '[i]f there is one factor which links these young Russian fantasists with their utopian predecessors, it is a recurrent theme of the infinite. ${ }^{, 7}$ According to Hatton the infinite and the complex are common unifying motifs in all of the paper architecture produced in the Soviet Union at that time. One of the key metaphors Hatton employs to describe the character of this architecture is 'a kind of matrioshka (the familiar toy of concentrically enclosing dolls) in the form of that most Russian symbol, the holy, magic Egg' ${ }^{28}$ This is the same metaphor that mathematician Manfred Schroeder uses to describe fractal geometry and the characteristics of infinitely scaled geometrical sets. ${ }^{29}$ A more subtle connection to fractal geometry is manifest in the use of pseudo-scientific terminology to describe the paper architecture. Tumarkin argues that these projects are formed from 'a complex sequence of images', ${ }^{30}$ which he claims are eminently suitable for depicting their architects' 'complex dynamic subject matter'. ${ }^{31}$ Ultimately, both Hatton and Tumarkin affirm that the key to understanding this architecture is found in the use of the concepts of complexity and infinity as a reaction against the 
monotony and stagnation of the architecture of the socialist city-state. That is, the fractal is appropriated in an attempt to represent the characteristics of complexity and infinity in architecture.

Russian paper architects were motivated by the desire to protest against a corrupted state architecture $^{32}$ and it is here that the political dimension of their appropriation is manifest most clearly. These designers argue that the socialist utopian dream is expressed architecturally in the form of endless, bland streetscapes with wind-swept public spaces. Thus, fractal architecture is adopted in these projects in an attempt to render the built environment less 'totalitarian', 'systematic', 'repetitious', 'stagnant' and 'utopian'. However, fractal geometry is not so inert, safe and malleable as these architects imagine and a close examination of two of the better-known projects, both of which were inspired by fractals, reveals the problems inherent in this assumption.

\section{Turin's The Intelligent Market}

W. Turin's enigmatic entry to the 1987 Japanese architectural competition The Intelligent Market depicts a fantasy surface structure that oscillates between various states of being; at once a drawing, a house, a building and a city grid. ${ }^{33}$ At the top of the main display panel a Menger sponge is clearly seen dominating the page. Several of the voids in this geometric icon are filled with bars, curtains, mullions, tension structures and trussed steel-frames (see figure 6). Two of the main voids are also finished in such a way that they are suggestive of Le Corbusier's model housing scheme from The City of Tomorrow and its Planning. ${ }^{34}$ This Menger sponge structure, which appears to be a tracing from the original Blumenthal and Menger drawing used in most books of fractal geometry in the 1970s and early 1980s, is folded, as if it were a section of a drawing, into the lower part of the panel.

The lower sections of Turin's panel are, at their most obvious level, an elevation of the facade of a Menger sponge. However, this vision is broken-down through a process of collage so that the geometry of the sponge is read in different ways in different parts of the diagram. To the left side of the panel the voids are projected out of the sponge so that they cast shadows, giving the impression that they are an aerial view of a city grid. The imposition of the plan of a church at the same scale (along with a few curved roads) reinforces the idea that the Menger sponge is used as the generator of a street grid and urban space. However, this impression is eroded near the middle of the panel where a figure is depicted reclining in a chair as if looking out of a window (void) in the facade. The shadows cast by the city-like projections and the form of the chair blend together, further fragmenting the page and challenging the idea of a single scale in the drawing; an appropriate reading of the fractal property of scaling. Below the reclining figure, one of the voids is projected into a familiar axonometric view of 
a Menger sponge, seemingly suggesting that at this point in the drawing the fractal is only abstract geometry and not an elaborate curtain wall or an endless urban landscape. The outline of the architect's hand (and the fingerprints that are smudged across this axonometric projection) further reinforce the idea that it is a drawing at full scale. Below the reclining man another of the voids is turned into a billboard that declares that 'the intelligent market develops as endlessly as our intellect. Therefore the intelligent market is a fractal' ${ }^{35}$ The figure of Philip Johnson seems to be reading the billboard from his doorway (another extended void within the sponge). He stands on a series of folds in the paper that metamorphose into a ground-line. Similar folds that divide the panel resemble the horizon, mountain ranges or contour lines.

In The Intelligent Market Turin uses the idea of the surface of the Menger sponge being a facade as a means of attacking the seemingly fixed scale of an architectural work. The design fluctuates continuously between states of ornamental and structural meaning. As surface ornament, the fractal is a subversive element designed to break down the concept of spatial certainty and predictability. As structure the fractal judiciously captures the idea that intelligence and memory cannot be quantified, controlled or spatially defined. This proposed relationship between the sciences of complexity and the capacity of the mind and memory is used in other architectural works for similar reasons. ${ }^{36}$ Turin's project, rather like the mathematician Kaye's proposed fantasy design for a 'fractal house for Topological Alice', ${ }^{37}$ is a shrewd use of the spatial characteristics of fractal geometry. ${ }^{38}$ Neither The Intelligent Market nor Alice's house can exist in the real world; both projects acknowledge the difficulty of working with fractals in built forms and play upon the absurdity of such an idea.

The appropriation of the Menger sponge also fulfils another more explicit purpose. The Menger sponge provides Turin with a bridge between paper architecture and real architecture - between the architect's imagination and the state's power to control construction. On one level, The Intelligent Market is defiantly paper architecture; the folds and fingerprints on the surface of the drawing exaggerate the media and its limitations. On another level, the Menger sponge transforms the paper architecture into real architecture; something which the laws of the state forbid without clear sanction. Specifically, the shifts in scale encouraged by the fractal icon are used by Turin to meld the abstract pencil drawing into the modernist utopias of Le Corbusier and Johnson; the architecture that in the hands of Brezhnev's state boards became so destructive. In this way, Turin uses the power of the mind (the infinite capacity of intelligence) to render his own architectural imaginings as realistic as those of Brezhnev’s state architects. 


\section{Bush, Podyapolsky and Khomyakov's The Cube of Infinity}

At the same time that Turin transformed the Menger sponge into a structure for storing intelligence, Dmitry Bush, Dmitry Podyapolsky and Alexandre Khomyakov proposed a variation of the Menger sponge as a means of overcoming the scale problems inherent in the relationship between the city and the home - a theme which resonates with that of Turin's project. In the description of The Cube of Infinity project (also known as Endlessness in a Cube), Bush, Podyapolsky and Khomyakov state that there is a 'contradiction between the urban space of today and the requirements of organizing the urban environment. The city is an unruly, chaotic and often decaying organism'. ${ }^{39}$ The Cube of Infinity attempts to break down the relationship between the city, the building and the environment. The fantasy structure they propose resembles a giant cube that has had the centre third of each of its surfaces removed (the first step in the generation of a Menger sponge). The surface of the cube thus created becomes a series of facades and the gaps between facades. Each of these facades is further broken down into window openings in individual buildings and then into mullions within window openings. The buildings depicted in this way are further layered, seemingly drawn in perspective, yet really all in the same plane, simultaneously displayed at different scales.

Bush, Podyapolsky and Khomyakov describe the complex surface of the 'BLOCK' as 'absolutely sterile and blank ${ }^{40}$; seemingly a form of endless camouflage which allows the building to blend into the urban environment and hide its inhabitants (see figure 7). They say that it is 'designed as a means of protection against the city. ${ }^{41}$ The facade is scale-less (or at least operates at many scales) and thus lacks true 'architectural details'. The facade appears to seal 'off the dwelling from the unhealthy surrounding of the city and turns the dwelling into a bulwark of man's private life'. ${ }^{42}$ Inside the block an endless grid of spatial divisions breaks down the volume into tiny cells, infinitely small corridors and vast cubic voids and air-shafts. While the outside uses the metaphor of the city as the infinitely perforated facade of the Menger sponge, the inside plays with the idea of an endless sequence of reducible spaces.

For Hatton, the architects' design 'conceives a minimalist block, mute against the outside but with a mirror-lined courtyard to become a solipsistic chamber for the inward gaze' ${ }^{43}$ The architects themselves describe the project in terms of '[p]ure infinity [...] crystallizing in the midst of chaos. ${ }^{44}$ It is chaos that

makes us turn our home into isolated structures, into specific worlds with their own inner development [...] Isolation and spirituality are assuming great importance today [...] no wonder then that the interior is our main concern [...] The way to free the individual is by 
overcoming individuality, breaking through the wall of banality built from the bricks of selfexpression. $^{45}$

\section{In the Service of Politics}

Both The Intelligent Market and The Cube of Infinity utilise the particular fractal geometric capacity of the Menger sponge in different ways but each fails to heed Evans' warning against assuming that geometry is theoretically inert. For example, while the fractal icon assists Turin in his attack on the socialist utopian ideal it also simultaneously subverts his design in several ways. Firstly, it is notable that the brief for the Intelligent Market competition was inspired by the writings of Friedrich Hayek, a twentieth century economist and political philosopher who was critical of fascist planning structures and supportive of socialist, market economies. ${ }^{46}$ In essence, the brief Turin was celebrating was designed to support an idealised version of the political systems he was attempting to undermine. On a more architectural level, the voids in the Menger sponge very closely resemble the endless windows of the Soviet office buildings that Turin wishes to reject. These same voids generate an infinite number of identically proportioned 'Corbusian' studio apartments; surely the epitome of Brezhnev's state architecture. While the fractal does allow Turin to transform the scale of his drawing into the scale of the city it paradoxically also transforms his city of imagination into the totalitarian architectural forms of communism. At the heart of this interpretative disjunction is the assumption (made by Hatton and Rappaport as well as Turin) that fractal geometry is capable of furthering a political agenda. While a particular use of fractal geometry in architecture may encourage a political dimension to suffuse the design this is at best an ambiguous proposition. Fundamentally, Turin seems unaware that the classical fractal he appropriates is transforming his own imagination and intellect into a utopian nightmare just as efficiently as it performs the reverse role.

The Cube of Infinity also uses a self-same fractal as a response to a totalitarian political system. If, as Rappaport argues, the sign of a totalitarian utopia is endless repetition then the architects should seek to use statistically self-similar fractals (those that simulate nature) rather than self-same or classical forms which are infinitely repetitious. ${ }^{47}$ Ironically, the Menger sponge, which is used to generate an infinite variety of facades, acts as a form of urban camouflage that hides rigidly arborescent, banal and monotonous interiors. It seems unlikely that this is intended as an satirical interpretation of the inevitability of utopian dreaming in Russia, regardless of how well hidden the private space is. Other projects by Bush, Podyapolsky and Khomyakov, including Interplay (1984), Glasstonehenge (1986) and, to a lesser extent, Mon Plaisir (1985), attest to their fascination with endless reflections and infinitely divisible spaces; all depicted without any obvious political irony. 
Robin Evans asserts that if geometry is to perform a foundational or formative role in architectural design it must, metaphorically speaking, be stable, inert, or dead.

From the point of view of the architect seeking firmness and stability, the best geometry is surely a dead geometry [...] What I mean by a dead geometry is an aspect of geometry no longer under development from within. [...] Dead geometry is an inoculation against uncertainty. ${ }^{48}$

Dead geometry provides stability for the generation of architectural forms and theories - it creates 'certainty in situations beset by doubt'. ${ }^{49}$ However, fractal geometry is not dead and fittingly, for Evans, the inevitable result of such a false assumption is that the appropriated body of geometry will become animate once more and will 'revive, like a monster'. ${ }^{50}$ Fractal geometry is a 'monster' precisely because many architects assume that it is sufficiently tame, dead or inert that they can use it to support any and all propositions. This is especially the case when appropriations of fractal forms in architecture are motivated by the desire to advance a political agenda.

Politics is innately concerned with power structures and the relationship between the individual and the state. In a meta-political sense, Jacques Rancière argues that 'politics' arises when the dominant structures and values of the state (the 'police order') are seen to be disrupted. ${ }^{51}$ Because the production of architecture for political purposes typically presupposes a particular imbalance of power, critical designs will usually deploy themes, devices, or symbols to undermine or subvert this 'police order'. This is why the application of fractal geometry is potentially problematic, not because it is recent, nor even because it might be poorly understood, but rather because it is being deployed for a particular purpose for which it is ill-suited.

The attacks on the architecture of Brezhnev's Soviet Union propagated in The Intelligent Market and the Cube of Infinity ultimately fail to achieve their goals precisely because they are founded on fractal geometry. These attacks, to borrow Evans' terminology, falsely presuppose that fractal geometry is dead and is therefore capable of being used to achieve a political end. As fractal geometry is foundational in these endeavours the architectural and theoretical proposition in these works is rendered unstable. It is this instability that allows the dramatically conflicting readings of the two projects highlighted in this paper. 


\section{Figures}

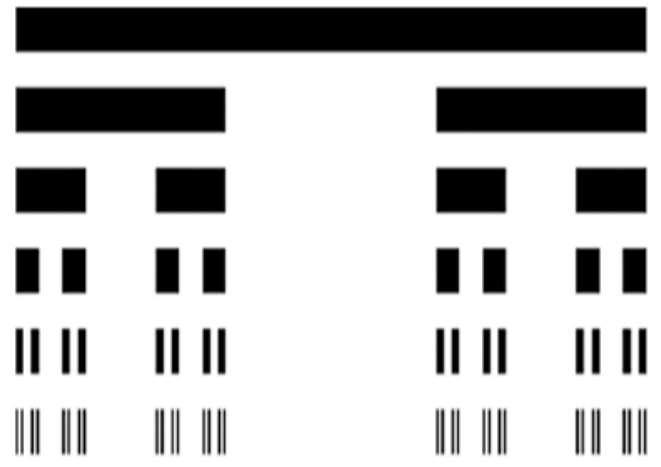

Figure 1. Classical fractal set, Cantor Dust, iterations $1-5$
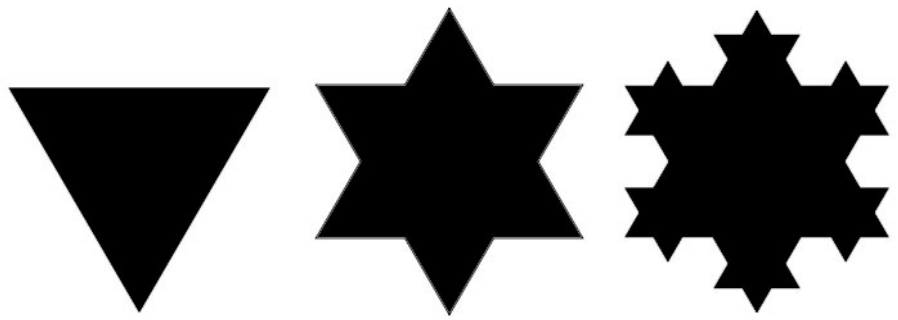

Figure 2. Classical fractal set, Koch Island, iterations 0, 1 and 2.

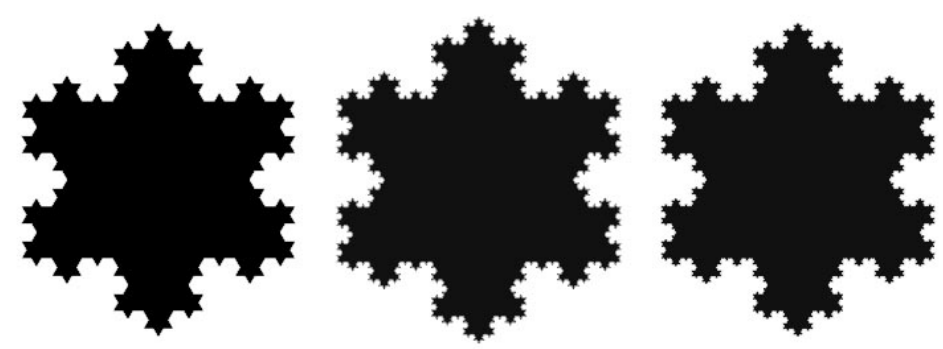

Figure 3. Classical fractal set, Koch Island, iterations 3, 4 and 5. 


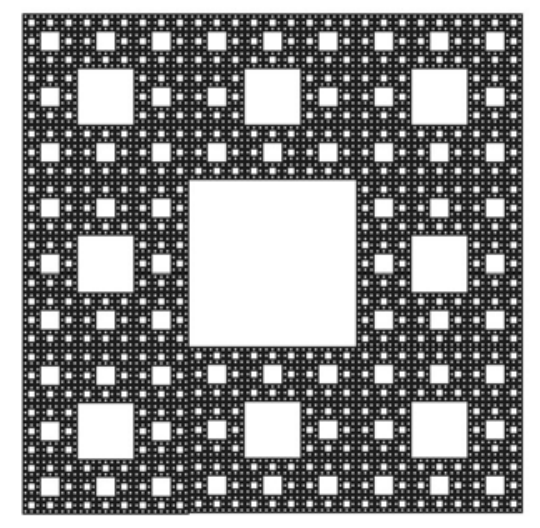

Figure 4. Classical fractal set, Sierpinski Carpet, iteration 7.

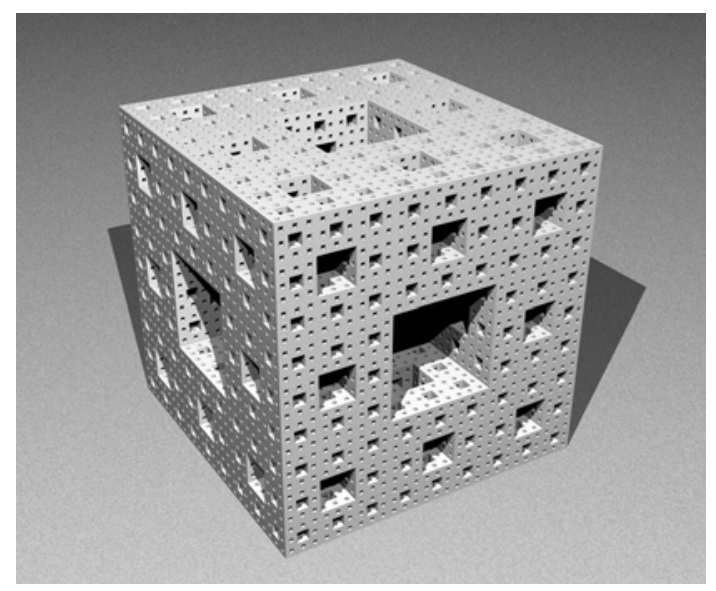

Figure 5. Classical fractal set, Menger Sponge.

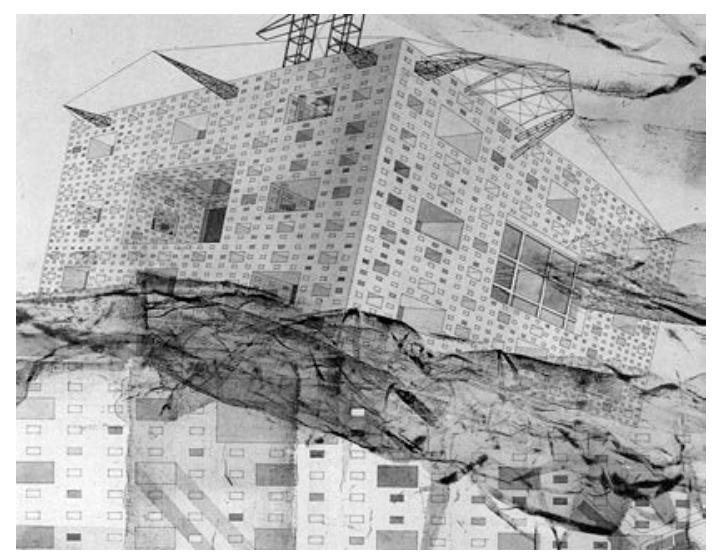

Figure 6. The Intelligent Market (1987) by W. Turin, (detail of upper panel). [Image copyright W. Turin 1987]. 


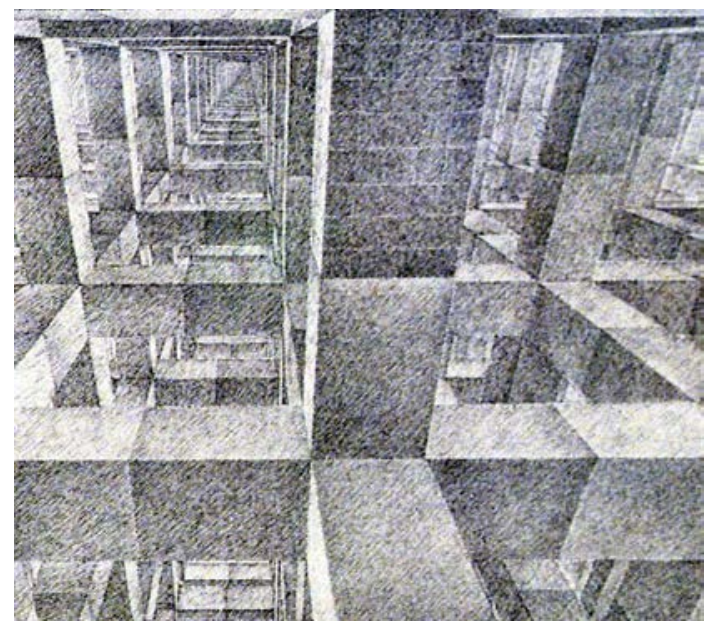

Figure 7. The Cube of Infinity (1987) Dmitry Bush, Dmitry Podyapolsky and Alexandre Khomyakov (interior detail). [Image copyright Bush, Podyapolsky and Khomyakov 1987,].

\section{Endnotes}

\footnotetext{
${ }^{1}$ Benoit B. Mandelbrot, Fractals: Form, Chance, and Dimension, San Francisco: W. H. Freeman and Company, 1977 P 4.

${ }^{2}$ Benoit B. Mandelbrot, The Fractal Geometry of Nature, New York: W. H. Freeman and Company, 1982.

${ }^{3}$ Peter Eisenman's House 11a marks a critical point in the relationship between architecture and complexity science. See: Michael J. Ostwald, and R. John. Moore, 'Spreading Chaos: Hayles' Theory and an Architecture of Complexity' Transition, 52/53 (1996): 36-53.

${ }^{4}$ Jean-François Bédard, (ed), Cities of Artificial Excavation: The Work of Peter Eisenman, 1978-1988, Montreal: Canadian Centre for Architecture, 1994, p 54.

${ }^{5}$ There are historic buildings which possess limited fractalesque patterns but these are examples of the intuitive or accidental use of geometry. No other examples have been found of the conscious appropriation of fractal geometry between the date the geometric theory was published in English (August 1977) and Eisenman’s presentation on the topic (July 1978).

${ }^{6}$ Peter Eisenman, 'Eisenmanesie', Architecture + Urbanism, (August, 1988) at 70.

${ }^{7}$ Michael J. Ostwald, 'Fractal Architecture: Late Twentieth Century Connections Between Architecture and Fractal Geometry’ Nexus Network Journal, Architecture and Mathematics, 3, 1 (2001): 73-84

${ }^{8}$ Michael J. Ostwald, 'Fractal Architecture: The Philosophical Implications of an Iterative Design Process,' Communication and Cognition, 36, 3-4 (2003): 263-295.

${ }^{9}$ Ironically, most classical fractals are strongly hierarchical and rigidly structured; characteristics which many architects and philosophers (notable including Deleuze and Guattari) have failed to appreciate. See: Gilles Deleuze and Felix Guattari, $A$ Thousand Plateaus: Capitalism and Schizophrenia, Minneapolis: University of Minnesota Press, 1987.

${ }^{10}$ Note that fractals simulate nature, they are not, as many architectural theorists claim, the geometry of nature. See the discussion on this important distinction in: Noel Gray, 'Critique and a Science for the Sake of Art: Fractals and the Visual Arts.' Leonardo, 24, 3, (1991): 317-20.

${ }^{11}$ Philip Steadman, The Evolution of Designs: Biological Analogy in Architecture and the Applied Arts, London: Cambridge University Press, 1979.

${ }^{12}$ Robin Evans, The Projective Cast: Architecture and its Three Geometries, Cambridge, Massachusetts: MIT Press, 1995.

${ }^{13}$ Michael J. Ostwald and R. John Moore, 'Icons of Nonlinearity in Architecture: Correa, Eisenman, van Eyck.' in Vikramaditya Prakash (ed) Theatres of Decolonization: (Architecture) Agency (Urbanism). Vol. 2 Seattle: University of Washington, 1997, 401-422.
} 
${ }^{14}$ See: Michael J. Ostwald, 'Fractal Traces: Geometry and the Architecture of Ushida Findlay.' In Leon van Schaik (ed) Ushida Findlay, Barcelona: 2G, 1998, 136-143

${ }^{15}$ Hans Lauwerier, Fractals: Endlessly Repeated Geometrical Figures, London: Penguin Books, 1991 p. 33.

${ }^{16}$ James Gleick, Chaos: Making a New Science, London: Macdonald and Co,1987p. 99.

${ }^{17}$ Brian H Kaye, A Random Walk through Fractal Dimensions, Cambridge: VCH Publishers, 1989 p. 32.

${ }^{18}$ See: Leonard Blumenthal and Karl M. Menger, Studies in Geometry, San Francisco: W. H. Freeman and Company, 1970.

${ }^{19}$ Blumenthal and Menger paraphrased in: John Rajchman, 'On Not Being Any One (52 min 12 sec),' in Cynthia C. Davidson (ed), Anyone, New York: Rizzoli, 1991 p.108.

${ }^{20}$ An exhibition of selected works by Paper Architects was also staged at the Architecture Association in the UK in 1988.

${ }^{21}$ Michael J. Ostwald, 'Rancière and the Metapolitical Framing of Architecture: Reconstructing Brodsky and Utkin's Voyage,’ Interstices, 8 (2007): 9-20

${ }^{22}$ Heinrich Klotz (ed), Paper Architecture: New Projects from the Soviet Union, New York: Rizzoli, 1989 p.7.

23 Ibid.

${ }^{24}$ Mikhail Belov, 'Children of the Stagnation', in Nostalgia of Culture: Contemporary Soviet Visionary Architecture. London: Architectural Association, 1988; at 6.

${ }^{25}$ Rappaport, Alexander G. 'Language and Architecture of Post-Totalitarianism,' in Heinrich Klotz (ed), Paper Architecture: New Projects from the Soviet Union. New York: Rizzoli, 1989, 11-16; at 12.

${ }^{26}$ ibid at 13 .

${ }^{27}$ Hatton, Brian. 'Voices from the Courtyard,' in Nostalgia of Culture: Contemporary Soviet Visionary Architecture. London: Architectural Association, 1988, 27-71; at 40 (my italics).

28 ibid at 60 .

${ }^{29}$ Manfred Schroeder, Fractals, Chaos, Power Laws: Minutes from an Infinite Paradise, New York: W. H. Freeman and Company, 1991, p. 84.

${ }^{30}$ Tumarkin quoted in: Catherine Cooke, 'A Picnic by the Roadside or Work in Hand for the Future?' in Nostalgia of Culture: Contemporary Soviet Visionary Architecture. London: Architectural Association, 1988, 11-26; at 18.

31 ibid.

${ }^{32}$ Klotz, Paper Architecture, p. 7.

${ }^{33}$ The Utopia Foundation Archives in Moscow credits this project to V. Tyurin not W. Turin, as books and catalogues have repeatedly done since the 1980s. This paper uses the early attribution and spelling which is the most common form. The archives also offer an alternative translation of the project text as follows: 'The intelligent market develops as endlessly as our intellect. Therefore, the intelligent market is a fractal. The fractal sponge is a system of through trusses with no useful space but with an infinite number of links. Each element of the system is being replaced with a similar one.'

http://www.utopia.ru/english/item.phtml?id=135\&type=graphics\&sortby=title\&start=150 [checked October 2009].

${ }^{34}$ Le Corbusier, The City of Tomorrow and its Planning, London: Architectural Press, 1971.

${ }^{35}$ W. Turin, 'The Intelligent Market,' in Heinrich Klotz (ed), Paper Architecture: New Projects from the Soviet Union, New York: Rizzoli, 1989, 90.

${ }^{36}$ See: Michael J. Ostwald, ‘Chaos and Memory’ Transition, No. 46 (1994): 62-69.

${ }^{37}$ See: Kaye, A Random Walk through Fractal Dimensions, pp. 404-406.

${ }^{38}$ See: Michael J. Ostwald, Fractal Architecture: Knowledge development within and between architecture and the sciences of complexity. Saarbrücken: VDM, 2009.pp 153-165.

${ }^{39}$ Dmitry Bush, Dmitry Podyapolsky and Alexander Khomyakov, 'The Cube of Infinity’ in Heinrich Klotz (ed), Paper Architecture: New Projects from the Soviet Union, New York: Rizzoli, 1989, p. 105.

${ }^{40}$ ibid.

41 ibid.

42 ibid.

43 ibid. 
${ }^{44}$ Bush, Podyapolsky and Khomyakov paraphrased in: Hatton, 'Voices from the Courtyard,' at 43.

${ }^{45}$ Bush, Podyapolsky and Khomyakov quoted in: Hatton, 'Voices from the Courtyard,' at 43-44.

${ }^{46}$ Friedrich A. Hayek, The Constitution of Liberty, (Chicago: University of Chicago Press, 1960); Friedrich. A. Hayek, 'The Use of Knowledge in Society,' American Economic Review, XXXV, (1945), 519-530.

${ }^{47}$ There are even statistically self-similar versions of the Sierpinski carpet. See: Kaye, A Random Walk through Fractal Dimensions, p 265.

${ }^{48}$ Evans, The Projective Cast, p. xxvii.

49 ibid.

50 ibid.

${ }^{51}$ Jacques Rancière, The Politics of Aesthetics, London: Continuum. 2004. 